\title{
ATTEMPTED INTERSPECIFIC MATING BY AN ARCTIC SKIPPER WITH A EUROPEAN SKIPPER
}

Peter Taylor

P.O. Box 597, Pinawa, MB R0E 1L0, E-mail: <taylorp@granite.mb.ca>

At about $15: 15 \mathrm{~h}$ on 3 July 2011, I observed a prolonged pursuit of a European skipper (Thymelicus lineola) by an Arctic skipper (Carterocephalus palaemon). This took place along Alice Chambers Trail $\left(50.17^{\circ} \mathrm{N}, 95.92^{\circ} \mathrm{W}\right)$ near the Pinawa Channel, a small branch of the Winnipeg River in southeastern Manitoba. This secluded section of the Trans-Canada Trail passes through moist, mature mixed-wood forest with small, sunlit openings that offer many opportunities to observe and photograph butterflies and dragonflies during the summer months.

The skipper pursuit continued for about four minutes, and I obtained 14 photographs, four of which are reproduced here (Fig. 1, see inside front cover). The behaviour appeared to be attempted courtship, rather than a territorial chase or feeding assembly. Fig. 1a shows the European skipper nectaring on a clover flower, but the Arctic skipper's proboscis is not extended. Whenever the European skipper took flight, the Arctic skipper followed a few centimetres behind (Fig. 1b). Whenever the European skipper landed on flowers or other low vegetation, the Arctic skipper alit just behind or to one side, often approaching within a few millimetres (Fig. 1a,c,d). One image, unfortunately not sharply focused, shows the Arctic skipper's abdomen curved sideways in a J-shape, almost touching the tip of the European skipper's abdomen in what appears to be a copulation attempt (Fig. 1d). Frequent short flights by the European skipper may have been an attempt to discourage its suitor - a known tactic used by unreceptive female butterflies ${ }^{1}-$ but it may simply have been disturbed by my close approach. Otherwise, the European skipper showed no obvious response to the Arctic skipper's advances.

These two species are classified in separate subfamilies (Arctic skipper in Heteropterinae, European skipper in Hesperiinae). Both species are only slightly dimorphic, and while the Arctic skipper's behaviour indicates it was a male, it is not certain that the European skipper was a female. The European and Arctic skippers are known in Britain as the Essex and chequered skippers, respectively, the last name being easily confused with the common checkered skipper (Pyrgus communis) of the Americas. The European (Essex) skipper is an invasive, introduced species in North America, while the Arctic (chequered) skipper is one of the few skipper species to occur naturally (as different subspecies) in both Eurasia and North America. The Arctic skipper is locally common, and 
the European skipper is sometimes abundant in the Pinawa area, but there is little overlap in their flight periods, which usually peak in southern Manitoba in the first halves of June and July, respectively. ${ }^{2,3}$ Contact between adults of the two species is thus limited, and this observation involved a late-surviving Arctic and an early-emerging European skipper.

In common with many small butterflies, the Arctic skipper is a territorial perching species. Field studies in Scotland showed that males sought mates by establishing small territories where they perched in low vegetation, typically $40-50 \mathrm{~cm}$ above ground, and flew out to intercept passing insects or to inspect the boundaries of their airspace. ${ }^{4}$ Interactions with bees or other butterfly species were typically brief - an average of $2.8 \mathrm{~s}$; even with females of the same species, they lasted only $12 \mathrm{~s}$ on average and rarely led to mating. ${ }^{4}$ The pursuit described here is thus unusual for its long duration (about 250 s), especially when a different species is involved.

It seems odd that the boldly marked Arctic skipper, relatively easy for humans to identify, would not recognize the much plainer European skipper as an inappropriate mate (Fig. 1), but the markings may have no function in mate recognition. Perhaps the European skipper's flight characteristics are similar enough to an Arctic skipper's movements to give a visual miscue. An olfactory miscue is also possible, but I have found no information on pheromone chemistry in either species.

In a previous note on a similar observation involving Milbert's tortoiseshell (Nymphalis milberti) and mourning cloak ( N. antiopa) butterflies, three records were cited of courtship behaviour between butterflies of different families or subfamilies. ${ }^{5}$ A brief survey of articles in the Journal of the Lepidopterists' Society (accessible online at http://peabody.research.yale.edu//jls/) indicates, however, that actual copulation or hybridization, whether stimulated under laboratory conditions or observed in the wild, usually involves butterflies of the same or closely related genera.

1. Opler PA, Krizek GO (1984) Butterflies east of the Great Plains: an illustrated natural history. Johns Hopkins University Press, Baltimore, MD.

2. Klassen P, Westwood AR, Preston WB, McKillop WB (1989) The Butterflies of Manitoba. Manitoba Museum of Man and Nature, Winnipeg, MB.

3. Taylor P (1989) Skippers and butterflies of the Pinawa-Lac du Bonnet region, southeastern Manitoba. Blue Jay 65:89-100.

4. Ravenscroft NOM (1994) Environmental influences on mate location in male chequered skipper butterflies, Carterocephalus palaemon (Lepidoptera: Hesperiidae). Animal Behaviour 47:1179-1187.

5. Taylor P (2007) Unusual behaviour involving mourning cloak butterflies. Blue Jay 65:158-160.

In seed time learn, in harvest teach, in winter enjoy.

- William Blake 